\title{
La familia rural navarra a comienzos del siglo XV
}

\author{
Peio J. Monteano *
}

\begin{abstract}
RESUMEN
Dos fuentes inusuales elaboradas en Navarra entre 1427 y 1437 permiten el estudio de su población bajomedieval tras casi un siglo de continuo deterioro demográfico y económico a causa de las epidemias, hambrunas y agobiante presión fiscal. En cuanto a la composición del hogar se aprecia la importancia de los núcleos familiares complejos, especialmente en el norte

del reino, $y$ un número medio de

individuos por fuego que oscilaría entre 4,5 y 5 . La estructura demográfica se caracterizaría por la abundancia de niños menores de 12 años, el reducido peso de los adolescentes y las altas tasas de masculinidad, reflejo todo ello de las dificultades planteadas por la coyuntura de aquellos años de continuo declive demográfico.
\end{abstract}

\begin{abstract}
Two unusual sources from Navarra dated between the years 1427 and 1423, make possible the study of its population during the late middle ages, after almost a century of a continuous decreasing economy and demography, due to starvation, hunger and overwhelming taxes. In relation to households structure, it has to be noticed the complexity of the family core, specially in the north part of the kingdom, and an average number of members by family between 4,5 and 5 . The characteristics of the demographic structure are the high presence of children below 12, the low number of teenagers and the high number of males; reflecting the difficulties derived from the situation during those years of a continuous decreasing demography.
\end{abstract}

¿Qué pobre es nuestra documentación! Así de expresivo se muestra Fossier cuando se lamenta de la sombra en que sumen las fuentes al hogar medieval, sombra que dificulta, cuando no hace imposible, nuestro conocimiento del mundo de las mujeres -esa "mitad invisible"-y de la infancia. $Y$ es que nuestro acercamiento a esta realidad tan escurridiza como es el

* Licenciado en Geografía e Historia (UNED), Licenciado en Sociología y Doctor en Historia (Universidad Pública de Navarra - Nafarroako Unibertsitate Publikoa). 
grupo doméstico bajomedieval hemos de hacerlo a través de documentos, ahora más abundantes debido al perfeccionamiento de las técnicas administrativas y fiscales que llevaron a cabo los estados y las comunidades urbanas.

Si bien es cierto que poseemos un mayor número de recuentos que permiten romper la impenetrable oscuridad que rodea a la demografía en los siglos anteriores, no lo es menos que trata en general de censos por unidades impositivas o "fuegos", no de individuos. Y ya sean globales o detallados, por localidad o por barrios, tienen en común el que no informan más que del número de fuegos, sin considerar su composición real y sin decirnos nada acerca del tamaño del hogar o de los miembros de la familia. Además de todo ello, y en lo que a la representatividad respecto a la población total se refiere, estas fuentes plantean otros problemas. Por un lado, es posible que no hayan sido censados mas que los fuegos capaces de pagar los impuestos, dejando de un lado a todos aquellos incapaces de contribuir. Por otro, es posible también que no se trate de fuegos "reales", sino fuegos de cuenta o fuegos "fiscales" que no tienen sino una remota relación con las familias existentes o con la situación demográfica. $Y$ finalmente, incluso cuando se tiene la certeza de que los fuegos son reales, resulta muy delicado precisar el número de habitantes, pues el uso de coeficientes arbitrarios es siempre arriesgado 1.

En este panorama, no resulta extraño que no abunden los estudios sobre la composición de la familia bajomedieval. Tan sólo fuentes de carácter excepcional han permitido estudios también excepcionales sobre la población de algunas regiones y ciudades como el Borbonesado, $\mathrm{Li}$ mousin, Pistoia, Verona y sobre todo Prato y Florencia ${ }^{2}$. En este último caso las investigaciones se basan en una documentación privilegiada -el catasto del Estado florentino realizado en 1427-1429 - la fuente que, con mucho, proporciona la información más considerable sobre una población medieval.

La situación en que se encuentran en Navarra los estudios sobre la familia y la estructura demográfica reflejan claramente la escasez de fuentes y la dificultad de su tratamiento que venimos señalando. No es extraño así que en 1982 Floristán Imízcoz afirmara, refiriéndose a ese reino, que sobre la composición familiar nada podía afirmarse con anterioridad al siglo XVIII. Sin embargo, dos años más tarde Berthe realizaba una vez más un novedoso estudio de la familia rural navarra hacia 1427-

1 BlockMANS-DUBOIS (1997): 200-203, y Fossier (1991): 391-395.

2 Germain (1995), Biget-Tricard (1981), Herlihy (1967 y 1973), Herlihy y Klapisch-Zuber (1978), entre otros. 
1433 basándose en los datos proporcionados por el fogaje elaborado en 1427-1428 y una encuesta sobre los labradores reales llevada a cabo poco después ${ }^{3}$.

\section{EL CRISTAL EMPAÑADO}

Así, pues, la documentación bajomedieval se nos presenta como un cristal empañado que apenas permite distinguir la silueta de la realidad familiar en el pasado. Ahora bien, si los recuentos generales posibilitan para el estudio de la población absoluta y las partidas sacramentales el acercamiento a la dinámica demográfica ya en la alta Edad Moderna, como acabamos de señalar, pocas fuentes permiten conocer la estructura de la población durante el periodo bajomedieval.

Llegados a este punto, hemos de resaltar una vez más la excepcionalidad de las fuentes fiscales navarras bajomedievales, fuentes que a pesar de su carácter no-demográfico nos permiten hoy día un acercamiento a la realidad de la familia en el primer tercio del siglo XV. La primera de ellas en el tiempo, es un fogaje que ofrece, es cierto, una información muy parca respecto al tema que estudiamos, pero referida a la mayor parte de Navarra. Por contraste, la encuesta de pecheros reales proporciona datos muy precisos, pero como puede observarse en el mapa adjunto, tiene un ámbito geográfico mucho más limitado.

Los "Libros de Fuegos de 1427-1428"

Tres volúmenes -con sus correspondientes copias del siglo XVIII-, contienen la encuesta fiscal que se realizó a comienzos del reinado de Blanca I y Juan II con el fin de «reformar» las tasaciones del impuesto de cuarteles, principal recurso económico de la monarquía navarra. De hecho, la información recabada fue utilizada por la Hacienda real para establecer las nuevas tasaciones fiscales de ese impuesto aplicadas ya en la recaudación de 14294.

Efectivamente, los Tres Estados del reino, reunidos en Cortes Generales en octubre de 1427, habian expuesto a los monarcas la necesidad de

3 FLORISTAN IMIZCOZ (1982) y BERTHE (1991): 67-83.

4 AGN. Comptos. Registro 395 , fol. $123 v^{2}$. En las cuentas de la ayuda recaudada en 1430, el recibidor de Estella afirma que "la quoal dicha refformacion o rellacion, bista e examinada por la Reyna nuestra seynnora et las gentes de sus finanças en grant Conseio, ha fecha cierta ordenança que començando en la dicha present aiuda et en adelant ayan de ser tacxados et paguen cada unos por todo el Regno en cierta manera et tacxa en aquella declaradas. 
actualizar las tasaciones que a principios del reinado de su predecesor Carlos III (hacia 1390) se realizaron con el fin de fijar la cantidad que debía pagar cada unidad contributiva (valles y villas) en las ayudas extraordinarias que, con carácter casi anual, se venían otorgando a la corona. En opinión de los diputados, debido a los cambios demográficos y económicos que se habían producido, la tasación antigua ya no se correspondía con la realidad del reino y para muchos pueblos resultaba insostenible el nivel de presión fiscal.

Atendiendo, pues, a las reiteradas súplicas de los Estados, el 20 de noviembre de 1427 los reyes designaban una comisión "por reformar e igoalar los fuegos" integrada por Miguel de Rosas, Martín de Cenboráin, Martín de Larrea, Martín Martíniz (alcalde de Cáseda), Pero Martíniz de Unzué, Lope de Eraso, Michelot de San Per (notario de corte) y Pere Arbeión o Lorenz (notario de Corella). Por su parte los notarios Joan Pasquier y Martín Ximénez de Sotés asistirian a la comisión 5 .

Seis días después la comitiva integrada por comisarios y notarios comenzó a recorrer el millar largo de localidades que se diseminaban por el reino, labor en la que empleó casi un año ${ }^{6}$. Los comisarios se personaban en la cabecera de cada unidad contributiva y en ella recogian por escrito, una a una, las declaraciones juradas de los vecinos de los diferentes pueblos y villas. Por mandato real, los aspectos acerca de los que se recababa información eran los siguientes: (1) Titular, rentas y cargas de la abadía, (2) clérigos que poseian bienes en el lugar, (3) relación de "moradores casa mantenientes", (4) vecinos foranos - no residentes pero con derechos-, (5) cargas que sostenía la comunidad, (6) provechos o rentas comunales, (7) modo de vida, (8) valor de los bienes de los vecinos, (9) disminución de la población en los últimos 20 ó 30 años y (10) tasación en el impuesto del cuartel. Los puntos primero, cuarto y octavo sólo aparecen en las primeras relaciones de la merindad de Estella.

La pesquisa fue realizada en todo el reino, empezando por la merindad de Estella y prosiguiendo por la de La Ribera-Tudela, Olite, Sangüesa, la Tierra de Ultrapuertos y la merindad de Las Montañas-Pamplona. Así lo atestiguan la acreditación de los pagos al precio de 15 sueldos diarios que constan en diversos recibos? ${ }^{7}$. Como ya hemos comentado, de los libros

5 AGN. Comptos Libro de Fuegos de la merindad de Las Montañas-Pamplona, fol. 1.

6 MONTEANo (1996): 311.

7 Efectivamente, que la encuesta fue realizada en todo el reino y no sólo en las merindades de las que nos han llegado los libros puede comprobarse en los recibos de los pagos realizados a los comisarios por recorrer las distintas merindades que constan en la sección de Comptos del AGN, cajón 126, carpeta 29, V (La Ribera-Tudela) y VI (Estella); carpeta 49, VII (Olite); carpeta 71, II (Las Montañas-Pamplona) y cajón 110, carpeta 10, LIII (Sangüesa). 
confeccionados han perdurado únicamente tres: los correspondientes a Estella, Sangüesa y Las Montañas-Pamplona.

Pese a el carácter excepcional de esta fuente y la importantísima información que proporciona, no pueden pasarse por alto que estos Libros de Fuegos presentan numerosas carencias que dificultan y relativizan su aprovechamiento demográfico. En primer lugar su carácter incompleto, pues como queda dicho, se han perdido los libros correspondientes a las merindades más meridionales (Olite y La Ribera-Tudela) y septentrionales (Tierra de Ultrapuertos), territorios con una estructura social y un régimen económico en gran medida específicos. Menor importancia tiene el hecho de que en fogaje también se excluya, debido a su régimen jurídico y tributario particular, la comunidad judía.

De la abundante información suministrada -11.541 fuegos repartidos en 712 localidades - aqui sólo vamos a servirnos de la que nos acerca a la composición interna de los fuegos. Y es que, a diferencia del resto de recuentos demográficos que poseemos para los siglos $X I V, x V$ y $X V{ }^{8}$, en los Libros de Fuegos de 1427-1428 nos encontramos con el enunciado de dos millares de fuegos que parece indicar que el hogar está integrado por más de un matrimonio. Así en Villatuerta se nos dice: "Item Maria Miguel Goyquoa con sus tres fijos casados en casa". Muy cerca de alli, en Legardeta se relaciona a «Joan Miguel et Johanco et Michel sus fijastros, todos tres con sus mujeres que biuen en una casa" ${ }^{9}$. Y ejemplos de este tipo suponen casi la quinta parte de los relacionados y su presencia es especialmente intensa, como veremos, en las zonas más norteñas. Son enunciados que, sin ninguna duda, reflejan la complejidad del hogar, sobre todo si tenemos en cuenta que muchos otros se limitan a consignar unicamente al titular de fuego.

No obstante, han de hacerse algunas precisiones acerca de criterios aplicados a la hora de confeccionar la tabla que sirve de base a este estudio.

En primer lugar, las viudas han sido contabilizadas como fuegos femeninos simples. Algo parecido hemos hecho con los huérfanos ("criazones"), considerados como fuegos masculinos simples. Los señores palacianos (nobles rurales) han sido considerados, en cambio, fuegos masculinos compuestos, pues se supone que contarían con criados para el desempeño de tareas domésticas y agrícolas. Los fuegos de población flotante, pegujaleros, mozos soldaderos, estajeros, etc. han sido considerados como fuegos masculinos simples. Por último, no se han incluido fuegos cuando se indica que han fallecido.

8 MONTEANO (1999)

9 AGN. Comptos. Libro de Fuegos de la merindad de Estella, tol. 171-173. 


\section{La «Encuesta de pecheros reales» (1433-1437)}

Apenas un lustro después de ese fogaje, en 1433 los mismos monarcas, deseando poner orden en sus rentas tras la epidemia de peste y guerra sufridas entre 1428 y 1430 , ordenaron a varios oidores o jueces auditores la Cámara de Comptos (organismo fiscalizador de la hacienda real) que se informasen sobre el estado en que se encontraban los labradores que pagaban sus tributos o pechas a la corona. En cumplimiento de este mandato, a partir de noviembre de ese año y hasta mayo del siguiente, Johan Garcia de Lizasoain, Sancho de Iturbide y Johan de Atondo recorrieron las merindades de Las Montañas-Pamplona, Estella y Olite, mientras su compañero Martín Garcia de Racxa hacía lo propio con la de Sangüesa, todos ellos «visitando et informandose del estado, poderío et facultat en que son pervenidos los conçeios de nuestros labradores" ${ }^{10}$. Su objetivo era sin duda valorar las posibilidades de tributación que tenían los pecheros reales tras los embates de la peste y la guerra. Tal vez se dejó para más adelante la realización de la misma comisión en la merindad más meridional, la de La Ribera-Tudela. Así parece indicarlo una indagación similar realizada en 1437 por los oidores Sancho de Iturbide y Johan de Atondo en la localidad de Cascante.

Con los datos recabados, los comisarios elaboraron a los reyes un detallado informe en el que hicieron constar la relación de fuegos pecheros, su composición familiar, el ganado con el que contaban, el nivel de endeudamiento y el importe de pecha que pagaban. Asimismo, se hacian observaciones acerca de la riqueza personal y la feracidad de la tierra, reflejando los comisarios su particular evaluación acerca de las posibilidades de mantener e incluso incrementar su aportación tributaria.

De esta encuesta -que, como hemos dicho, se realizó en todo el reino- tan sólo se han conservado cuatro fragmentos en su mayoría referidos, como puede observarse en el mapa, a localidades de la merindad de Estella (valles de Améscoa, Arana, Allin, Berrueza, San Esteban, Guesálaz, Yerri, asi como localidades de la Sonsierra y Ribera Estellesa) y, más sucintamente, de la de Olite ${ }^{11}$. Otro pequeño fragmento de esta encuesta fue encuadernado en el siglo XVIII junto al Libro de Fuegos de 1366 y seguramente por ello y por carecer de fecha hasta ahora habia sido datado en ese año ${ }^{12}$. Se refiere a varias localidades de la merindad de Sangüesa (valles

10 AGN. Comptos. Cajón 146, carpeta 11, IX.

1 AGN. Comptos. Registro 557, fol. 363 y siguientes y Cajón 184, carpeta 3, ff. 10-16, éste último fechado erróneamente en 1429.

12 No hay ninguna duda de que ese fragmento pertenece a la encuesta de 1433-1434. Además de ajustarse a su estructura, en ambas aparecen cinco fuegos homónimos, comenzado por Martín Périz, al que coinciden en denominar como el alcalde. 
de Elorz, Aranguren, Lizoain, Ayechu y localidad de Luzaide/Valcarlos) ${ }^{13}$. Por último, la información referida a Cascante consta en un cuadernillo separado fechado como hemos dicho en $1437^{14}$.

De todos estos fragmentos parece que Berthe conoció tan sólo dos - seguramente los recogidos en el Registro 557 y en el citado Libro de Fuegos de 1366-, por lo que nuestro análisis puede ser más completo debido a la información adicional que hemos obtenido ${ }^{15}$.

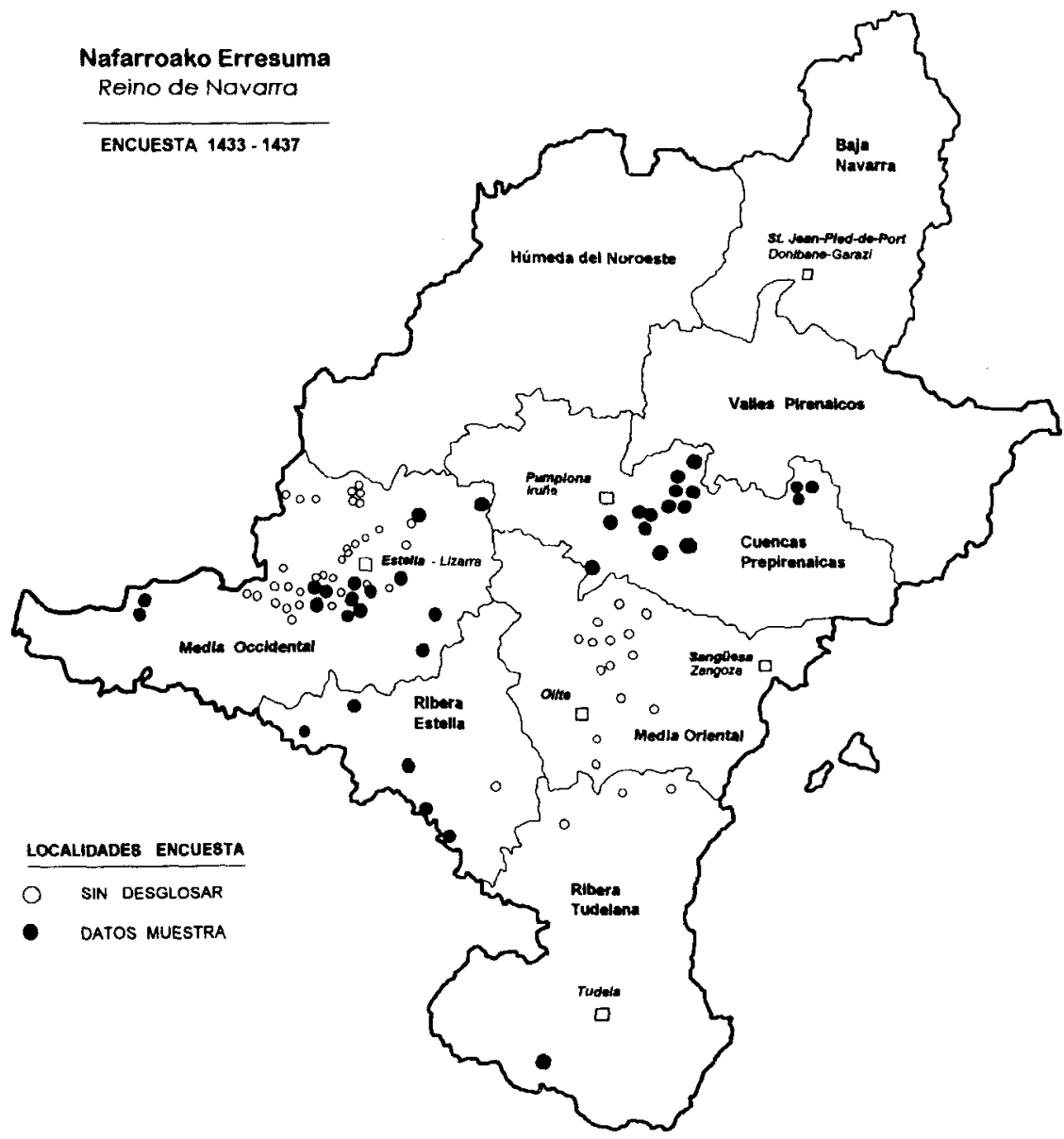

13 CARRASCO (1973): 657-668.

14 AGN. Comptos. Papeles Sueltos. Prímera seríe. Legajo 7, carpeta 25.

15 BeATHE (1991): 71. 
A pesar de su fragmentación y relativa concentración geográfica, esta fuente proporciona una información excepcional para el estudio de la familia rural navarra en una época tan temprana como el primer tercio del Cuatrocientos. $Y$ es que, aunque no en todas las localidades, los oidores de Comptos que la elaboraron hicieron constar detalladamente la composición de las distintas familias labradoras, cuál era el ganado con el que contaban $y$ el nivel de endeudamiento. $Y$ como para muestra vale un botón, veamos cómo se describia un fuego de Cascante:

«Item Martin de Oynuesta, casado, de hedat de $L X$ aynos poco mas o menos. Et ha III fijos, el mayor esposado, de XX años, et quatro fijas, la una casada et las otras tres de XIIII aynos en iuso. Et los otros dos fijos, el uno de XVI aynos et el otro de XIIII. Et lavra con un iunto de azemillas et tiene un par de ieguas con sus crianças et un rocin et una asna et un asno et dos bacas et ata $C$ cabeças de ganado menudo. Et es cargado en la dicha pecha en II cafizes, III quartales, I almut de pan meytadenco. Es endeudado en $L X X$ florines et $V$ cafizes de trigo mesura vieja ${ }^{16}$.

Como se ve, esta sucinta descripción permite definir la unidad familiar del cascantino Martín de lñuesta. Se trataría de un matrimonio de unos 60 años que tiene tres hijos (de 20,16 y 14 años) y tres hijas que pueden ser la mayor de 18, otra de 14 y dos menores de 12 años. Tenemos por tanto una familia integrada por nueve personas, cuatro hombres y cinco mujeres, o. lo que es lo mismo, cuatro adultos, tres o cuatro adolescentes y dos niñas pequeñas.

Desgraciadamente, no todas las descripciones de las unidades familiares son tan claras. En muchas de ellas sólo se consigna el titular del fuego, el ganado con el que cuenta y la pecha pagada. Sería el caso de «Johan Garcia, de edat $L X X X$ aynos, tiene II iuntas" (Muez). En otras se describe el fuego intentando reflejar únicamente su grado de complejidad o su fuerza de trabajo (el titular vive con otra pareja - hijo o hija casado en casa-): "Miguel Martiniz, de hedat de L aynos, tiene I fijo casado en casa; tiene I" iunta et paga XVI sueldos, III dineros en dineros. En pan meytadenquo I/ kafizes, I robo. En vino XII carabidos" (Learza). Como se puede apreciar, nada se dice si el segundo matrimonio tiene o no descendencia.

Para el aprovechamiento demográfico de estos datos hemos debido desechar, pues, estos fuegos cuya descripción superficial suscita dudas acerca de su verdadera composición. Ello ha podido reducir la representatividad de la muestra en cuanto a los fuegos compuestos, escasos en esta zona, pero que han sido desechados casi sistemáticamente. Distorsión ésta que

16 AGN. Comptos. Papeles Sueltos. Primera serie. Legajo 7, carpeta 25, fol. 5. 
no se vería sino acrecentada por la representatividad geográfica de la muestra, que en su mayoria se refiere a las zonas más meridionales dejando de lado la Montaña, donde el fuego complejo tenía, como veremos, mucho mayor peso.

De este modo hemos obtenido un total de 352 unidades familiares detalladas - repartidas en 37 localidades e integradas por 1.393 individuosque nos van a servir en nuestro estudio de la familia. Este número es incluso inferior al volumen de familias que con el mismo fin maneja Berthe en sus estudios (371), lo cual no deja de sorprender si tenemos en cuenta que aquí hemos contado con dos fragmentos más de la encuesta. Claro que este investigador francés se centra más en la estructura de la familia (simple/extensa) que en su composición. De todos modos, consideramos que ambos análisis no se contradicen y que son claramente complementarios dada la precisión y acierto con que el profesor Berthe realiza el suyo.

En cuanto al tratamiento de la información suministrada para los casi cuatro centenares de familias admitiremos que, a la hora de tabularla, hemos debido utilizar diversas categorías y criterios con el fin de compensar algunas deficiencias como, por ejemplo, la subrepresentación de la mujer o imprecisión de sexo o edad, esto último muy habitual hasta el siglo XVII. Así pues, para los casos dudosos se han seguido los siguientes criterios.

Cuando se indica que el titular del fuego está "casado" o simplemente se consigna su descendencia sin explicitar que esté viudo o viva sólo, se ha añadido a su cónyuge, atribuyéndole en este caso su misma edad. A esto último parece invitar la propia descripción de algunos fuegos de la merindad de Sangüesa («Item Miguel Garcia et su muger de edat de cada LV annos...", en Zuazu) que indicaría que las parejas no tenían grandes diferencias de edad y que cuando así era se hacía constar este extremo. Por lo demás, la propia holgura de los intervalos de edad que hemos utilizado permite realizar esta operación sin grandes riesgos.

Por otro lado, cuando se indica que se tienen hijos "por casar" sin precisar la edad, se les ha incluido en el grupo de 13-18 años, considerando que esta condición, por evidente, no se refería a niños. Para terminar, a los clérigos que se les consignan hijos o nietos se les ha considerado viudos, a pesar de que somos plenamente conscientes de que ha podido no ser así.

En todo caso, es cierto que los estos dos últimos criterios han sido aplicados en muy contadas ocasiones y que, por ello, de ser erróneos, habrian distorsionado muy poco los resultados.

De la descripción de las edades y de la finalidad de la propia encuesta -que desde luego no se origina por una interés demográfico estricto-, se deduce que los comisarios reales pretendieron reflejar, de un lado, la fuerza de 
trabajo humano y animal con la que contaba el núcleo familiar y, de otro, las cargas (hijos pequeños, padres inválidos, endeudamiento, pechas) que debía soportar. Desde el primer punto de vista se establecen cuatro grupos: los niños (menos de 12 años) que no trabajan y se consignan como carga familiar 0 fuerza futura; los adolescentes (entre 12 y 18 años), que trabajan como pastores, mozos, etc. pero aún no están casados; los adultos (entre 19 y 64 años), que aportan la principal fuerza de trabajo; y finalmente los viejos (más de 64 años) cuya fuerza de trabajo está muy limitada por la edad o la enfermedad.

\section{El contraste de los datos}

Antes de pasar a exponer los resultados del análisis, vamos a hacer algunas consideraciones acerca de la fiabilidad de los datos contenidos en los Libros de Fuegos. Como se ha dicho, contienen éstos el resultado de una exhaustiva encuesta realizada por comisarios reales en los pueblos de las merindades de Estella, Las Montañas-Pamplona y Sangüesa. Pero ¿hasta qué punto está recogida toda la información?

Efectivamente, por desgracia no podemos trasladarnos a la Navarra del primer tercio del siglo xV y comprobar la exactitud con que se recabó la información del fogaje de 1427-1428, especialmente la demográfica. Pero por suerte contamos con fragmentos de la encuesta realizada seis años después, entre noviembre de 1433 y mayo de 1434, por otros comisarios reales.

Aunque ambas fuentes se hallan distanciadas en el tiempo por seis años, un ataque de peste (1428-1429) y una guerra (1429-1430) hemos comparado la información disponible con dos objetivos. El primero, comprobar si existe correspondencia del número de fuegos labradores. Para ello, en los pueblos para los que se cuenta con el número de labradores tanto en 1427 como en 1434, se ha estudiado la variación producida. El segundo, observar si existe correspondencia en el grado de complejidad de los fuegos (simples-compuestos). En este caso hemos utilizado las relaciones en las que se detallan las personas que componen cada fuego.

Número de fuegos labradores

Los datos de 62 localidades permiten la comparación entre el número de labradores consignado en 1433-1437 y en 1427-1428. Al margen de ellas, en la primera fuente se nos proporciona información demográfica acerca de otras veintidós localidades de la Merindad de Olite, pero no es 
posible su uso a los fines descritos por la sencilla razón de que, como se sabe, para estas localidades no contamos con información en 1427-1428.

Del cruce de datos puede deducirse que se da una elevada coincidencia entre el número global de labradores de esas comunidades. En ellas constaba que existian en 1427 un total de 535 fuegos labradores frente a los 561 que se hacen constar seis años después. Es decir, teniendo en cuenta las variaciones y redistribuciones demográficas, hay una variación global de veintiseis fuegos ( 5 por ciento). A escala local, vemos que las variaciones en cada localidad son pequeñas, salvo el caso de Mendavia, donde en 1434 se hicieron constar trece fuegos más que en 1427.

Al margen de la coincidencia señalada -que sin duda viene a reforzar la «fiabilidad" de los Libros de Fuegos-cabe preguntarse cómo es posible que tras haber padecido un ataque de peste y una guerra cercana, estas comunidades rurales muestren tal estabilidad. En este sentido puede aducirse que tal vez en 1427, ante la inmediatez de un recuento fiscal, se haya producido cierto agrupamiento de fuegos, pues sabemos que era ésta una de las estrategias de fraude más utilizada. En este sentido en 1434 no se hubiera producido esa "contracción", pues, aunque la encuesta tiene también finalidades fiscales, se realiza más detalladamente e «in situ», con lo que disminuían las posibilidades de fraude.

\section{Tipos de fuego}

Como es lógico, al haber transcurrido apenas un lustro entre la realización de ambas encuestas, en muchos pueblos aparecen fuegos enunciando el mismo cabeza de familia tanto en 1427 como en 1434. En estos casos hemos comprobado si el enunciado múltiple que en la primera fuente hemos interpretado como "compuesto" se corresponde en realidad con familias complejas a la vista del desglose que de ellas se hace en 1434.

Hemos hallado un total de 181 fuegos homónimos de los cuales 152 (84 por ciento) coinciden con la interpretación hecha: considerar simples a los que se enuncian con el nombre del cabeza de fuego y compuestos los que sugieren la existencia de otro núcleo conyugal. Los 29 restantes (16 por ciento) no coinciden. Dada la fluidez que se produce en la configuración de los fuegos compuestos (un fallecimiento los convierte en «simples» rápidamente), podemos afirmar que, transcurridos seis años, esta variación o nocoincidencia es más que asumible.

Concluiremos, por tanto, afirmando que la interpretación respecto al grado de complejidad de los fuegos ha sido correcta. 


\section{LA FAMILIA RURAL}

No creemos descubrir nada nuevo si decimos que en Navarra durante el siglo $\mathrm{xV}$ la forma de agrupamiento humano más básica siguió siendo la familia, o mejor dicho, la "etxea", la familia-casa, un concepto a la vez demográfico y económico. Así, pues, la "casa" hace referencia tanto a un grupo de personas que vive bajo un mismo techo como al conjunto de la explotación familiar a la que aportan su fuerza de trabajo. En este sentido, la casa es considerada una unidad de consumo, pero también una unidad de producción ${ }^{17}$.

En el mundo rural navarro, el grupo doméstico se encarna, pues, en la etxea y en las tierras que de ésta dependen. Es precisamente por esa implicación económica -por su carácter de "empresa»-por lo que surge el "fuego", concepto que se generaliza en el siglo XIV y que considera a la casa como una unidad fiscal. Así, simplificando mucho, puede afirmase que cada fuego corresponde a una familia. Dado que las fuentes históricas de las que nos servimos en este estudio son de carácter tributario, nuestro acercamiento a la estructura familiar del Cuatrocientos sólo puede realizarse a través de la noción de "fuego", concepto que por su naturaleza fue definido por la administración y que, como veremos, resulta demasiado uniformizador y estático a la hora de reflejar una entidad tan variable en el espacio y en el tiempo como es la familia.

\section{Composición del fuego}

Sabemos que, aunque los recuentos fiscales nos los contabilizan de igual modo, el grado de complejidad de los fuegos oscilaba desde individuos solos a grandes familias compuestas, como hemos visto, por tres o cuatro parejas. La primera clasificación podría establecerse, así, entre fuegos solitarios, fuegos simples y fuegos complejos.

Los fuegos solitarios o sin pareja conyugal son aquellos en los que la célula familiar está rota o ni siquiera ha podido formarse. Se trata de individuos solteros o de viudos o viudas no vueltos a casar y sus hijos. En muchas ocasiones, no obstante, los individuos célibes no suelen estar contabilizados como fuegos independientes sino que constan en los fuegos donde prestan sus servicios como criados o aprendices. El número de esos fuegos solitarios suele aumentar en periodos de crisis demográfica, aunque nor-

17 Para un estudio más detallado de la equivalencia entre afuego" y "casa" véase MonTEANO (2000-2): 414-417. 
malmente no representa sino una etapa más, pues pronto son reconstituidos mediante un segundo matrimonio. Veámoslo con un ejemplo:

«Item Pero Benedit, de hedat de $\mathrm{XC}$ aynos et decaydo que non tiene muger nin criaturas, nin ganado ninguno, et paga trigo XVIII robos, ordio VIII robos, en dineros IX sueldos. Et paga la pecha vendiendo oy II pieça tras otra» 18.

Los fuegos simples o nucleares están constituidos por una pareja y su descendencia. Suele ser el tipo más numeroso, especialmente en los medios urbanos. Así encontramos en Cascante

"Item Garcia Miguel, casado, de hedat de XLV aynos poco mas o menos. Et ha tres fijos de $\mathrm{Vl}$ aynos en iuso. Laura con una iunta, tiene dos mulas con que laura et un asno de dos aynos. Et no a otro ganado et asaz es pobre et endeudado. Et es cargado en la dicha pecha en III cafizes un quoartal, dos almudes de pan meytadenco. Es endeudado en XLV florines e medio ${ }^{19}$.

Los fuegos complejos o polinucleares agrupan bajo un mismo techo a varias parejas conyugales. Las familias que constituyen este tipo de fuegos pueden ser "extensas" - una pareja más un viudo o viuda de la generación precedente- 0 «múltiples» - la pareja de los padres y la de un hijo casado, por ejemplo- En algunos casos, una familia múltiple está compuesta por las parejas de varios hermanos con sus respectiva descendencia. Sirva este ejemplo de Ayechu.

«Item Pero Periz, dicho Garraz, esta ciego, et su muger de edat de cada LXV aynnos. Tienen VIII creaturas, de los quoalles tienen en su casa dos fijos casados et vn fijo pastor et vna fijetta assaz chica. Et tiene vn nieto de edat de XIII aynnos et vn ganadero a soldada de edat de XIII aynnos. Labra con IIII buyes, tiene II yegoas, II mullos, III nouiellas. Tiene IIC $L$ cabeças de ganado menudo. Paga de pecha XXXV sueldos, VI dineros ${ }^{20}$.

Pero el fuego no es una realidad invariable. A lo largo del tiempo se hace y se deshace, se estructura y se desorganiza, al ritmo de generaciones y adversidades. El carácter estático del fuego fiscal recoge mal esa variabilidad, ese ciclo de la evolución familiar en la que se suceden fases "nucleares" y fases "complejas". Un fuego simple constituido por una pareja y sus hijos puede convertirse con el tiempo en polinuclear en cuanto uno de éstos se casa y tiene descendencia sin abandonar el hogar paterno. Años después, el fallecimiento de la primera generación puede devolverlo a su fase nuclear e

\footnotetext{
18 AGN. Comptos. Documentos. Cajón 184, carpeta 3, fol. 428.

19 AGN. Comptos. Papeles sueltos. Primera serie. Legajo 7, carpeta 25, fol. 2.

20 CARRASCO (1973): 667.
} 
incluso una epidemia desestructurarlo totalmente. Un nuevo matrimonio del cónyuge superviviente lo devolvería a su fase nuclear y asi sucesivamente.

Como se ha dicho, los Libros de Fuegos de 1427-1428 ofrecen ejemplos de toda esta tipología. Estudiando esta fuente, Berthe encuentra que aproximadamente un 30 por ciento de los fuegos eran de tipo compuesto. Este porcentaje, si bien no permite afirmar que la familia compleja constituía para los campesinos del primer tercio del Cuatrocientos el modelo familiar, infravalora el peso de este tipo de unidades familiares al reflejar tan sólo un momento concreto en su evolución.

En nuestra opinión, los datos que proporcionan tanto el citado recuento como la encuesta de 1434-1437 deben manejarse con sumo cuidado, pues pueden estar reflejando una situación muy concreta ya que la población acaba de sufrir una época especialmente negativa por el impacto de las pestes, malas cosechas y guerra reciente. En todo caso, el análisis debe contemplar la diversidad socio-geográfica del reino. Sólo de este modo puede observarse cómo, si bien los fuegos simples o nucleares constituyen casi ocho de cada diez fuegos navarros en 1427-1428, la importancia de los fuegos complejos aumenta conforme ascendemos hacia el norte. Efectivamente, si en la Sonsierra el predominio del fuego simple es casi absoluto, en las Cuencas Prepirenaicas las familias polinucleares ascienden al 22 por ciento y, más al norte, en determinadas zonas como los Valles Cantábricos su peso alcanza el 35 por ciento.

Debemos concluir, pues, que en las zonas ganaderas la presencia de la familia compleja o troncal parece ser más importante que en las de ocupación cerealista. Esta relación entre orografía y tipo de familia ha sido puesta también de manifiesto en otros territorios. Germain, por ejemplo, basándose en los registros de la talla de varias castellanías del Bobonesado a finales del siglo $\mathrm{xV}$, afirma que la densidad de los fuegos polinucleares sigue con bastante fidelidad el mapa del relieve alcanzando su máxima implantación (un 33 por ciento) en regiones accidentadas donde el aislamiento orográfico ha dado una mayor cohesión al grupo familiar. Por el contrario, los suelos más ricos de las llanuras habrían permitido una mayor definición de los fuegos $y$, por lo tanto, un predominio de los de tipo nuclear ${ }^{21}$.

Por otra parte, el número de fuegos encabezados por mujeres -en su inmensa mayoría, viudas - puede dar una idea aproximada del número de fuegos desestructurados. En 1350, por ejemplo, el número de fuegos femeninos en Laguardia alcanzaba casi la cuarta parte de los relacionados. Bilbao y Fernández de Pinedo atribuyen aumento de estos fuegos a las rupturas matrimoniales provocadas por la peste y cuando alcanzan un porcentaje

21 Germain (1995), 33-34. Se trata de las castellanias de Hérisson, Montluçon, Chantelle y Murat entre los años 1478 y 1517. 


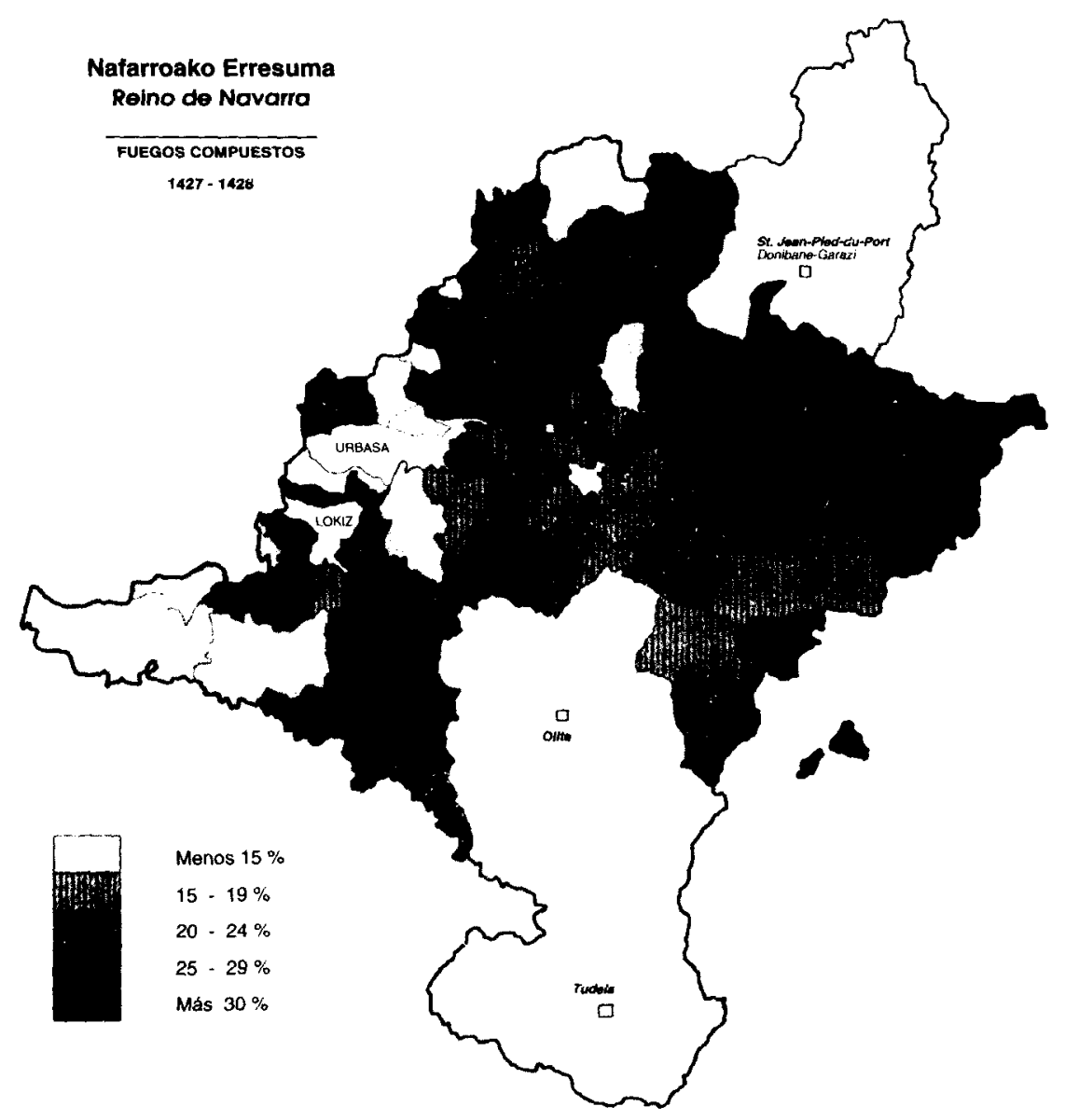

significativo (del 15 al 20 por ciento) consideran que el modelo familiar dominante es el nuclear ${ }^{22}$. En nuestro caso, y volviendo al mapa adjunto, este supuesto sólo podía ser contemplado nuevamente en las zonas más meridionales, ya que sólo en la Navarra Media el porcentaje de mujeres titulares de fuegos se acerca a los propuestos. Aunque faltan datos para las merindades del sur, en el resto del reino los fuegos femeninos apenas suponen uno de cada diez. Los fuegos solitarios encabezados por un hombre son más difícilmente detectables, bien por que el enunciado no permite distinguirlos del resto de fuegos masculinos, bien porque fueran menos numerosos debido a la frecuencia de las segundas nupcias entre los varones viudos.

22 Billaao-Feanández De Pinedo (1978): 154 
Dimensión de las familias

Sobre este aspecto, directamente relacionado con el espinoso asunto del coeficiente, nada nos dicen los libros de fuegos que relacionan contribuyentes y menos aún los apeos que únicamente los cuantifican.

A partir de la descripción de las familias pecheras que proporciona la encuesta de 1434-1435, Berthe ha podido llegar a la conclusión - por otra parte, presumible - de que existe una correlación entre la estructura y la dimensión de los hogares: las familias complejas duplican en miembros a las simples. Es más, para el investigador francés, ambos tipos de familia se diferenciarían esencialmente por el número de personas disponibles para explotar la empresa familiar, lo cual confería a las complejas una clara superioridad y unas mayores posibilidades de supervivencia ante las adversidades demográficas. El mismo autor advierte una relación entre la complejidad del hogar y su nivel de riqueza. Éste último queda de manifiesto en una mayor contribución en el impuesto de cuarteles - de base patrimonial- y en un mayor número de ganado, tanto de labor como ovino. No resulta difícil, por tanto, entrever una interrelación entre el número de brazos y la riqueza de la explotación. Un mayor patrimonio permite mantener una familia más numerosa mientras que ésta posibilita la prosperidad de la explotación ${ }^{23}$.

Navarra 1427-1428. Estructura de fuegos compuestos ${ }^{24}$

\begin{tabular}{lrrrrr}
\hline Número de parejas & Pamplona & Sangüesa & Estella & \multicolumn{1}{c}{ Total } & $\%$ \\
\hline Dos matrimonios & $\mathbf{7 4 2}$ & $\mathbf{6 2 4}$ & $\mathbf{3 5 2}$ & $\mathbf{1 . 7 1 8}$ & 91,9 \\
- Padres e hijo casado & 333 & 319 & 194 & 846 & 45,3 \\
- Padres e hija casada & 324 & 273 & 121 & 71 & 38,4 \\
- Hermanos y hermanas casados & 63 & 16 & 32 & 111 & 5,9 \\
- Diversos & 22 & 16 & 5 & 43 & 2,3 \\
\hline Tres matrimonios & $\mathbf{7 1}$ & $\mathbf{3 5}$ & $\mathbf{4 0}$ & $\mathbf{1 4 6}$ & 7,8 \\
- Padres y dos hijos & 56 & 30 & 34 & 120 & 6,4 \\
- Hermanos y hermanas casados & 1 & 0 & 1 & 2 & 0,1 \\
- Diversos & 14 & 5 & 5 & 24 & 1,3 \\
\hline Cuatro matrimonios & & & & & \\
- Padres y tres hijos & 4 & 0 & 1 & 5 & 0,3 \\
\hline TOTALES & $\mathbf{8 1 7}$ & $\mathbf{6 5 9}$ & $\mathbf{3 9 3}$ & $\mathbf{1 . 8 6 9}$ & $\mathbf{1 0 0}$ \\
\hline
\end{tabular}

La coexistencia de familias simples y complejas tiene, por tanto, consecuencias a la hora de calcular los efectivos demográficos absolutos a partir 
del número de fuegos, concepto que como hemos dicho refleja del mismo modo realidades demográficas distintas. Por un lado, deberfamos dar mayor peso al número de fuegos que los recuentos arrojan para las zonas norteñas, donde hemos visto que la familia compleja tiene mayor implantación. Por otro, debemos considerar si a to largo del Trescientos y det Cuatrocientos se ha producido lo que algunos denominan "reagrupamiento de linaje", o lo que es to mismo, si dada la superioridad de la familia compleja para superar las adversidades, tan frecuentes en este periodo, varias familias nucleares se han unido formando un nuevo y único fuego. Es éste un aspecto que los comisarios reales encargados de los recuentos fiscales tienen muy en cuenta. Así, en fecha tan temprana cemo el año 1350, los comisarios encargados de recaudar el impuesto del monedaje en la Tierra de Ultrapuertos interrogaban a sus informantes usi en una casa et unfuego ay dos o tres o mas que ayan bienes conoçidos" 25 .

Como bien indica Berthe, de haberse producido este fenómeno de agrupamiento de fuegos, deberían revisarse los cálcutos demográficos basados en los recuentos de fuegos, ya que éstos se han realizado partiendo de la hipótesis de una relativa estabilidad de la estructura familiar y del coeficiente de individuos por hogar. La multiplicación de familias "extensas* y "múltiples" -afirma el historiador francés- sálo puede hacerse en detrimento de la cantidad de fuegos y per tanto las estadísticas para los siglos XIV y XV tenderían a exagerar el índice real de despoblamiento.

Es el mismo Berthe quien despeja dudas. El grupo familiar complejo existla en Navarra ya en la primera mitad del siglo xiv y los datos no confirman la existencia hegemónica de una familia nuclear que, a raiz de los trastornos demográficos de la segunda mitad del Trescientos, evoluclonara hacia formas polinucleares. Con anterioridad las familias complejas estaban ya muy extendidas y, aunque sin duda las crisis favorecieron el proceso, éste no adquirió una intensidad suficiente para alterar las cifras 26 .

Otro factor que merece considerar es el del impacto de las epidemias en la demografia. Habitualmente nuestro estudio de la población se basa en la diferencia entre el número de fuegos que presentan los recuentos fiscales. Pero, en realidad la enfermedad no acaba con unas familias y deja indentnes a otras. Los fuegos supervivientes tamblén se ven reducidos en sus dimensiones y de hecho, en la encuesta de 1427-1428, son muchos los pueblos que afirman que on ellos no se ha corrado ningune casa) pero que han disminuido considerablemente en el nímero do personas. Les perdidas do-

25 AGN. Comptos. Documentos. Cajón 38, núm. 31, A 1-11-111, pliegos 1-33.

26 BERTHE (1991): 82-83. 
mográficas serían, pues, mayores que las que muestra la simple comparación del número de fuegos ${ }^{27}$.

Respecto a la estructura y dimensión de los grupos familiares, el estudio de las 352 familias que de forma completa son descritas en la encuesta de 1433-1437 no hace sino confirmar los datos proporcionados por los Libros de Fuegos de 1428-1429. Como hemos señalado, de los 181 fuegos homónimos que hallamos en ambas fuentes 152 mantienen la misma estructura - simple o compuesta-, una elevada coincidencia si tenemos en cuenta que han mediado un ataque de peste y una guerra con especial incidencia en los territorios a los que la información se refiere. En cuanto al número de miembros que componen el hogar, vuelve a comprobarse que su número desciende de norte a sur: las Cuencas Prepirenaicas contarían con una media de 5,1 personas por familia, la Tierra y Ribera estellesas contarian con 3,6 y la Ribera Tudelana con 4,3.

Dado que dos de cada tres familias descritas pertenecen a las zonas de menor relación fuego/personas, es lógico que la cifra global que obtenemos ascienda a 4 individuos por familia. Una cifra que indudablemente sería mayor si hubiésemos contado con información para la Montaña, zona donde hemos visto el peso de las familias complejas era notablemente superior y por lo tanto también el número de individuos con que contaban. Por último, el volumen de fuegos "urbanos", aunque reducido en términos relativos, también debería tenerse en cuenta dado su menor tamaño. Considerando todo ello, y a modo aproximativo podriamos afirmar que en la Navarra del Cuatrocientos el número medio de individuos por familia oscilaría entre 4,5 y 5 , aunque sin ninguna duda, como dice Fossier, también aquí se produciría una gran variación dependiendo de la época, la clase social y la zona geográfica ${ }^{28}$.

\section{ESTRUCTURA DE LA POBLACIÓN}

Nuestro conocimiento de este interesante aspecto de la población debe limitarse aún más debido al condicionamiento que imponen las fuentes. En este sentido, los únicos datos con los que contamos los proporcionan los tres centenares y medio de familias descritas de forma completa en la encuesta de 1433-1437. Gracias a ella conocemos a grandes rasgos los grupos de edad y el sexo de las aproximadamente mil cuatrocientas personas que las integraban. Los datos se resumen en esta tabla.

\footnotetext{
27 Monteano (2001): 117.
}

28 FOSSIER (1984): 24. 
La familia rural navarra a comienzos del siglo XV

Navarra (1433-1437). Estructura de la población

\begin{tabular}{|c|c|c|c|c|c|c|c|c|c|}
\hline \multirow[b]{2}{*}{ Zona } & \multicolumn{4}{|c|}{$\operatorname{EDAD}(\%)$} & \multicolumn{2}{|c|}{ SEXO } & \multirow[b]{2}{*}{$\mathbf{R m} * *$} & \multirow[b]{2}{*}{ fuegos } & \multirow[b]{2}{*}{ coet. } \\
\hline & $0-11$ & $12-18$ & $19-64$ & +64 & h. & m. & & & \\
\hline CUENCAS & 43 & 6 & 42 & 9 & 146 & 150 & 97 & 58 & 5,1 \\
\hline MEDIA OCCIDENTAL & 33 & 6 & 55 & 6 & 210 & 172 & 122 & 107 & 3,6 \\
\hline RIBERA ESTELLESA & 35 & 7 & 50 & 9 & 258 & 222 & 116 & 132 & 3,6 \\
\hline RIBERA TUDELANA & 38 & 5 & 52 & 5 & 129 & 106 & 122 & 55 & 4,3 \\
\hline Total & 37 & 6 & 50 & 7 & 743 & 650 & 114 & 352 & 4,0 \\
\hline
\end{tabular}

* $N=352$ familias.

** Pazón de masculinidad.

\section{Grupos de Edad}

Como puede verse, la población se caracteriza por el peso de dos grandes grupos de edad: los adultos constituyen la mitad de la población mientras que los niños suponen más de un tercio. Frente a ellos, el grupo de los adolescentes y de los viejos resultan muy exiguos. Con todo, también aquí se aprecian diferencias geográficas, ya que en la Cuenca de Aóiz-Lumbier - que podría reflejar la situación en la Montaña- es la única zona donde los niños son más numerosos que los adultos. No tenemos noticia de que en esta comarca hubiera sufrido en mayor medida el impacto de las dificultades, por lo que el fenómeno podría deberse más bien a la existencia de una corriente emigratoria desde una zona que, como ésta, debia estar saturada para sus posibilidades económicas. Corriente que llevaría a muchos jóvenes a emigrar hacia los centros urbanos del sur, tal y como parecen señalar los abundantes despoblados de la región de origen y las mayores relaciones de masculinidad en las de recepción 29.

Esta distribución nos confirma, pues, la imagen de una población con fuertes tasas de natalidad. Como ya dijimos al tratar de este tema, ésta era la única forma de garantizar el relevo generacional en una época plagada de epidemias y con una elevada mortalidad infantil. Y por ello la etapa de fertilidad femenina era aprovechada hasta los límites biológicos. De hecho, en la misma encuesta encontramos casos como el de Sancho García, labrador de Sesma, que a sus 75 años tenía un hijo de 8; Johan Grueso, octogenario de San Adrián que tenia un "fijo chico"; o de Miguel Martiniz, de 70 años, que tenia un hijo de 18 años y otros dos pequeños.

29 La composición por sexo la hemos medido a través del indicador denominado «Razón de masculinidad" ( $\mathrm{Rm}$ ) o cociente del número de hombres y mujeres, es decir, el número de varones existentes por cada cien mujeres. 


\section{Los adolescentes}

Pero sin duda es esa especie de "estrangulamiento" demográfico que jalona el paso a la edad adolescente uno de los aspectos más llamativos. Pese a que tal vez la encuesta ignora algunos muchachos que tempranamente abandonaron sus familias para trabajar como jornaleros o pastores, parece que esta omisión no es sistemática. Así, en el fuego de Pero Periz, alias Garratza, se incluye un ganadero a soldada de 13 años; en el de Miguel Periz y Pero Lopiz, su cuñado, figura un mozo de labor y en el de Miguel Xeméniz un mozo casi loco. El exiguo grupo de adolescentes sólo puede atribuirse a una sobremortalidad infantil y juvenil que hacía que fuesen muy pocos los niños que alcanzasen la madurez. Como veremos en el siguiente punto, determinadas pestes se cebaron en estos grupos de edad y aludiamos a la mortandad de los "mitjans" documentada en Cataluña en 1371. La fuente que manejamos reflejaría la sobremortalidad que padeció al menos la zona suroccidental del reino tras los embates de las pestes de $1400-1403,1410-1413$ y $1420-1423$, la hambruna de 1425 y la epidemia y guerra de 1428-1430. Estas dificultades habrían diezmado a las poblaciones más jóvenes.

¿Un momento coyuntural o un fenómeno estructural?. Para dilucidar la cuestión hemos tenido que desglosar el grupo de los adultos (de 20 a 64 años) basándonos en la edad declarada por los titulares de fuegos y suponiendo que sus esposas tendrían aproximadamente la misma edad, algo que, como ya hemos dicho, en líneas generales parece sugerir ta propia fuente. Pues bien, con todo las limitaciones que posee esta estimación por décadas de nacimiento, vemos cómo efectivamente la distribución es más regular. Las generaciones a partir de los 30 años son notablemente más nutridas y van progresivamente reduciéndose conforme avanzan en su ciclo vital.

La estructura de la:población que muestra la encuesta de 1433-1437 reflejaría, oues, las dificultades planteadas por el hambre y las epidemias do 1420-1425 y por la peste y la guerra de 1429-1430. De la intensidad con que éstas afectaron a la zona de nuestro estudio da buena idea el testimonio recogido en la misma encuesta referido a la tocalidad de Piedramillera: “Todos los sobradichos [20\} son fuego mantenientes. Nota que en este lugar auia ante de la guerra XL iugadas et morieron en la mortaldat çaguera LXXV personass 30 . Es decir, que la localidad habría perdido casi la mitad de su población. Así que, dada la periodicidad con que estas dificultades se sucedieron durante el siglo XV, no es aventurado suponer que situaciones similares afectaran a cada generación. En 1415, por ejemplo, a los co-

30 AGN. Comptos. Documentos. Cajón 184, carpeta 3, fol. 400 (nota marginal). 


\section{Estructura demográfica (1433-37)}

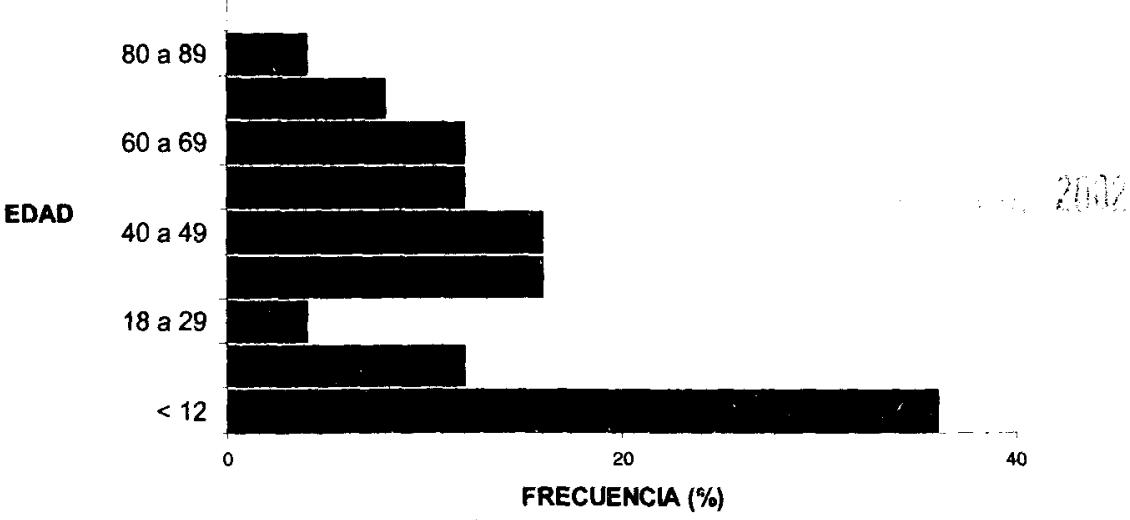

misarios reales que visitaron Castillo-Nuevo les llamó la atención el hecho de que al margen de los adultos no hubiera más que niños menores de diez años ${ }^{31}$. No sería, pues, hasta que en el primer tercio del Quinientos remitiera el impacto las epidemias cuando en Navarra se darían circunstancias favorables para el despegue demográfico que muestran los apeos del siglo $x V^{32}$.

\section{Las mujeres}

Para terminar dedicaremos unas líneas a las mujeres, pues el estudio de la población por sexos es una de las extrañas posibilidades que ofrece esta fuente. Llaman la atención las elevadas tasas de masculinidad que arrojan los casi cuatro centenares de familias que hemos estudiado. Efectivamente, aunque la razón de masculinidad $(\mathrm{Rm})$ global es de 114 hombres por cada cien mujeres, las zonas más meridionales del reino muestran una bastante mayor, llegando a 122. Unas tasas que destacan aún más a la luz de sus valores actuales, claramente favorables al género femenino.

¿Se debe a una ocultación en las fuentes?. La encuesta, desde luego, tiene una clara finalidad económica y por ello no olvida consignar a todos

31 AGN. Papeles sueltos, segunda serie. Legajo 10, carpeta 122 (Castillo-Nuevo) "sin menores algunos sino que sian criaturas de cada $I X$ a $X$ aynnos et di a yuso et aqueillas muyt pocas".

32 Monteano (2000): 56-60. 
los adolescentes que, cumplidos los 12 años, podían aportar su fuerza de trabajo a la explotación familiar. A decir verdad, en muchos casos se indica que el titular del fuego está casado, pero nada se dice de la esposa. Pero en otros casos se nos indican que todos los descendientes de la pareja son hijas, consignando su edad. Nada hace pensar, por tanto, en una determinante infrarrepresentación de las mujeres y en Cascante, localidad en la que no se ha planteado ninguna duda a la hora de clasificar la población relacionada, es precisamente en donde la razón de masculinidad alcanza el valor más elevado $(\mathrm{Rm}=122)$.

Tenemos que deducir por tanto que, a la luz de estas informaciones, en el primer tercio del siglo xv había muchos más hombres que mujeres. Este hecho se debería a una mayor mortalidad femenina a consecuencia del parto e incluso a una mayor mortalidad infantil de las niñas. Algo que, dicho sea de paso, era bastante común en el resto de Europa pues, como afirma Fossier, la relación numérica de sexos hasta 1400 ó 1450 parece favorable aún a los hombres, con una razón de masculinidad de entre 127 y 129 hombres por cada centenar de mujeres ${ }^{33}$. Sólo las Cuencas muestran una clara diferencia con respecto al resto de zonas. Aquí, efectivamente, la relación de sexos es ligeramente favorable a las mujeres $(\mathrm{Rm}=97)$. Ello podría deberse como ya hemos dicho a la existencia de una corriente migratoria que hace que muchos jóvenes solteros abandonen la comarca con destino a otras zonas, a la Navarra Media y Ribera presumiblemente. La situación podría ser similar en toda la Montaña, que tradicionalmente ha sido una tierra de emigrantes debido a la fácil saturación de sus posibilidades económicas. Sería, en suma, el mismo fenómeno que explica las bajas tasas de masculinidad que Mikelarena encuentra en Bera y Ezkurra a principios del siglo XVII $(\mathrm{Rm}=67)^{34}$.

\section{CONCLUS!ONES}

\section{El Catasto florentino}

Para concluir, vamos a comparar los resultados obtenidos en la $\mathrm{Na}$ varra rural con los que arroja otra fuente coetánea - el Catasto florentino de 1427- si bien somos plenamente conscientes de que en este caso se trata de un territorio bastante alejado y de un medio eminentemente urbano.

33 FOSSIER (1991): 394.

34 Mikelarena (1990): 117. 
El examen del Catasto revela que la unidad de recuento y de tasación en Florencia y su comarca era el fuego $u$ hogar integrado por un matrimonio que convive y constituye la unidad de consumo y de producción. También aqui y siguiendo la sucesión patrilineal, en algo más de la cuarta parte de los fuegos del contado cohabitaban varias generaciones, si bien en la ciudad de Florencia este porcentaje se reducía notablemente. En cuanto a sus dimensiones, el fuego toscano arroja una media de 4,4 personas de media, si bien el rural aparece más nutrido que el urbano. Aunque el hogar más corriente era el de dos personas, algo más de la mitad de los individuos integraban fuegos de más de seis. La correlación entre riqueza y dimensión del fuego es también aquí positiva, incluso en el campo. Las familias ricas albergan más niños que las familias pobres, pero esta relación es compleja.

También en la Toscana de 1427 encontramos una razón de masculinidad muy elevada $(R m=110)$, mayor en la ciudad que en el campo y máxima en la capital, aunque inferior a la observada en Navarra. Después de una corrección cautelosa de los factores de distorsión ${ }^{35}$, puede observarse que la pirámide de edad se caracteriza por el escaso peso de las cohortes adolescentes en relación a una plétora de ancianos y una amplia base infantil. Es el resultado de unas vidas minadas por las pestes y de su eco en las generaciones siguientes. El equilibrio entre edades no se recuperará mas que a partir de 1470 .

El Catasto - y otras fuentes también - muestra una edad media de matrimonio de 18-19 años para las mujeres y 27-28 para los hombres en la ciudad, y de 19 y 23-24 respectivamente en el campo.

Completemos esta información con los datos proporcionados por los registros de sepulturas. Para los años cercanos a los del catastro florentino, la tasa bruta de mortalidad es como mínimo del 36,4 por mil, tasa que se lógicamente se eleva en las edades más tempranas hasta alcanzar el 40,6 por mil. La sobremortalidad de algunos años se aprecia claramente. Como en la actualidad, las mujeres vivían más años que los hombres y por ello habia muchas más viudas. La principal causa de fallecimiento era la peste, seguida, entre los varones, de las enfermedades intestinales y, entre las mujeres, de la vejez. Y se moría mucho más en verano que en otras estaciones ${ }^{36}$.

35 Según Louis Henry éstos se derivarian de la falta de inscripción de niñas, la atracción de las edades múttiplos de diez superior en las mujeres, falta probable de inscripción de mujeres en edad avanzada, etc. HENRY, (1980): 29.

36 BLOCKMANS-DUBOIS (1997): 211-212. 


\section{La coyuntura: guerra y peste}

La foto fija que de la sociedad navarra nos proporcionan tanto el fogaje de 1427-1428 como la encuesta de 1433-1437 no puede ser interpretada sin atender a la influencia que en ella ha podido tener la coyuntura. En este caso, es forzoso referirnos a las epidemias de peste, periodos de malas cosechas y «crisis mixtas» - coincidencia de hambre y enfermedad- que se han producido en los años inmediatamente anteriores a la elaboración de ambas fuentes.

Gracias a la privilegiada documentación navarra, hoy día conocemos bastante bien la sucesión de epidemias de peste que padeció el reino desde 1348 a $1653^{37}$. El siglo xv se inauguró con una nueva mortandad durante los años 1400 a 1403, de inusitada violencia y extensión, que pudo acabar con más de la décima parte de la población navarra. Una década más tarde y acompañada por la hambruna causada por la seguía, la plaga reapareció en Navarra afectando al parecer con especial intensidad a las comarcas más meridionales. Los años siguientes parece que fueron relativamente buenos, pues las fuentes no señalan ningún accidente climático notorio.

Mejor documentada aún tenemos la hambruna que con carácter general padeció el reino entre 1421 y 1425 . Está década fue precedida por unos años secos (1416-1418) y otros muy lluviosos y fríos (1419-1420) que se tradujeron en destructoras riadas. Las cosechas de 1420 y 1424 fueron especialmente malas y, además, desde ese primer año la peste volvió a recrudecerse extendiéndose por todo el reino, siendo especialmente mortífero el año 1422.

Tras una relativa calma, en 1428 la plaga vuelve a golpear amplificando sus efectos cuando al año siguiente comienza la guerra contra Castilla. Este enfrentamiento tuvo especial incidencia en las comarcas suroccidentales del reino, zona a la que, recordémoslo, corresponde la mayoría de la información de la encuesta sobre pecheros reales ${ }^{38}$.

Que estos avatares tuvieron especial incidencia en la demografía de la zona estudiada lo pone de relieve los testimonios que poseemos referida a las localidades de Azagra, Sesma y San Adrián, donde residían nada menos que 75 de las familias utilizadas en nuestra muestra. Pues bien, el 23 de abril de 1402 el rey condonaba a Azagra el pago de sus impuestos por cin-

37 Monteano (1999): 171-207. Para este tema también se remite a nuestro libro de próxima aparición "La ira de Dios. Los navarros en la era de la peste (1348-1725)".

38 MONTEANO (1999): 146-149. 
co años en consideración a la gran mortandad que la villa ha padecido recientemente ${ }^{39}$. Doce años más tarde es la cercana localidad de Sesma la que obtiene una remisión similar debido a la persistencia de las mortandades y de la sequía ${ }^{40}$. Por último, en 1421 era San Adrián la que veía reducidas sus cargas tributarias considerando los daños causados por las crecidas del Ebro y las pérdidas humanas originadas por la peste ${ }^{41}$.

Ninguna duda, pues, sobre el impacto que las malas cosechas, epidemias de peste y guerra han tenido en la zona.

\section{Desnatalidad $y$ "efectos onda»}

Para terminar, y sin pretender hacer un estudio exhaustivo del tema, veamos el impacto que todas estas dificultades - especialmente la peste, sin duda principal causa de mortalidad de la época - han podido tener sobre la estructura demográfica que refleja el estudio de nuestras fuentes.

Como ya señalamos, en las sociedades de régimen demográfico antiguo - como la Navarra de los siglos $x \mathrm{~V}$ y $\mathrm{XV}$ - la elevada mortalidad ordinaria sólo podía ser compensada mediante un número de nacimientos habitualmente también elevado. Desde luego, a corto plazo los efectos de las epidemias sobre la natalidad no podian ser menos que negativos, pero de la capacidad de recuperación demográfica dependía en que sus consecuencias a medio o largo plazo se hiciesen notar en la estructura de la población.

El matrimonio es de entre los fenómenos demográficos que documentan los libros sacramentales el más racional y más planificado. La escasez de subsistencias y la presencia de la enfermedad que caracterizan a las "crisis mixtas" de las que venimos hablando se traducen en un clima psicológico general nada favorable a la celebración de matrimonios. A ello habría que sumar las huidas y fallecimientos. Para restablecer la tasa de nupcialidad ordinaria debía esperarse a que la muerte recuperara también

39 AGN. Comptos. Registro 256, fol. 96 v*: El rey se dice "certifficado de la grant mortaldat que ha seydo en el dicho logar de poco tiempo aqua por la quoall las gentes del dicho logar son muy fuert diminuydos et mengoados" (23.IV.1402).

40 AGN. Comptos. Registro 332, fol. 64. La remisión se justifica: "por causa de las mortaldades que y han contenuado son tanto diminuydos del numero que solian ser que en ninguna manera eillos supportar ni pagar non podrian las cargas ordinarias et extraordinarias que han. Et no res menos que por la grant sequa et mengoa de agoas que han ouido en los aynnos passados et en este present no han cuillido pan ni bino para lur prouision solament..." (28.IX.1414).

41 AGN. Comptos. Registro 368, fol. 134: «por quoanto el rio de Ebro lis ha entrado et destruyto cierto termino et do eillos se sostenian et trayan sus ganados. Et bien assi por quoanto la mortaldat ha siguido en el dicho logar et son tanto diminuydos del numero que solian ser. Et por esto non podian soportar las cargas reales..." (25.II.1420). 
su ritmo normal. Pero con todo, este movimiento oscilante del número de matrimonios no está ocasionado exclusivamente por la presencia de la peste, sino que responde a un conjunto de causas tanto demográficas como económicas, psicológicas o sociales.

Además de por la caída de la nupcialidad - la inmensa mayoría de los hijos se tienen en el seno del matrimonio-, el descenso de la fecundidad contribuye a agravar la crisis de natalidad. La "amenorrea del hambre" y el estado depresivo general son la causa de que el número de concepciones se reduzca. A ello habría que sumar algunas formas de control voluntario de los nacimientos que, aunque no documentados ni Navarra ni en esta época, bien pudieran haberse practicado en este reino. Así en Castilla se denunciaba la práctica del infanticidio en Medina del Campo (1599) y entre algunas familias rurales de la comarca de Ciudad Rodrigo (1603). Por otro lado, en 1607 un tratadista jesuita combatía en sus aspectos morales la utilización del "coitus interruptus» como medida anticonceptiva. La misma abstinencia sexual recomendada por los médicos (el doctor Gebara lo hacia también en Pamplona durante la peste de 1599) y el fallecimiento de mujeres gestantes debieron contribuir decisivamente al descenso de la natalidad en los momentos inmediatamente siguientes a las epidemias ${ }^{42}$.

La sobremortalidad femenina y el recrudecimiento de la mortalidad infantil a causa de las epidemias que defendía Bennassar han sido puestos en duda por varios autores. Appleby considera que es el grupo de los jóvenes comprendidos entre los 10 y 35 años, es decir, ni los muy jóvenes ni los muy viejos, el más castigado por la peste bubónica en los tiempos modernos. Pérez Moreda, por su parte, defiende que el predominio corresponde a la mortalidad adulta ${ }^{43}$.

En cuanto a Navarra se refiere, la estructura por edades que nos proporciona la excepcional Encuesta sobre pecheros reales en 1434-1435 vendria a confirmar la visión de Bennassar y Appleby. Como hemos visto ya, en ella las generaciones nacidas entre 1404 y 1424 aparecen totalmente diezmadas (especialmente la de los años 1404-1414) a la vez que se constatan unas tasas de masculinidad bastante elevadas. Y no debe ser una situación particular del momento, pues también Leroy señala cómo los testamentos de los burgueses de Tudela testimonian en 1361, 1375 y 1383 gran cantidad de hogares destruidos donde los cabezas de familia, las mujeres embarazadas y los niños de corta edad mueren en espacio de pocos días ${ }^{44}$. Las cifras facilitadas en Egüés (1566) y Pamplona (1599) confirmarían aunque con pre-

\footnotetext{
42 Perez Moreda (1980): 285.

43 Perez Moreda (1980): 273-274.

44 LeROY (1984): 241.
} 
cauciones tanto la sobremortalidad femenina como la infantil. En la capital dos de cada tres víctimas adultas son mujeres y en Egüés, aunque no se nos detallan las víctimas, llama la atención el número de niños y jóvenes arrebatados por la peste.

La desnatalidad causada por el descenso de la fecundidad y los desastrosas consecuencias de la mortalidad infantil sólo podían traducirse en generaciones maltrechas cuyos efectos negativos sobre la estructura de edades se incrementarían cuando años después llegaban a la edad de matrimonio. Quiere esto decir que las epidemias, al margen de la mortalidad inmediata, proyectaban sus nefastas consecuencias en el futuro mediante los llamados "efectos de onda", es decir, se traducian en un descenso de nacimientos unos veinte años después de haberse producido. Tal vez a ello se deban las paternidades tardías a que haciamos referencia al tratar de la familia. La fecundidad sería explotada hasta sus límites biológicos y así hallamos madres al borde de la menopausia y padres octogenarios. El mejor ejemplo lo hemos visto ya al tratar de la estructura de la población en 14331437. Los estragos producidos por la epidemia de 1420-1423 y, en menor medida, por la de 1429-1430 se habian traducido en una pirámide de edad donde destacaban por su importancia el número de niños y adultos.

Un ejemplo de la desestructuración de familias que se producía nos lo ofrece el caso de doña Urraca de Ubani quien en 1415 exponía su situación: anciana y casi ciega, recientemente había fallecido su nieto Martín Ferrándiz - el sostén de la casa- con lo que su familia se habia visto reducida a cuatro biznietos menores de siete años. En resumen, de cuatro generaciones sólo habian sobrevivido cinco miembros de las extremas (bisabuela-biznietos) y en situación muy precaria como puede suponerse ${ }^{45}$.

La observación de que incluso en los periodos de entrecrisis la población continuaba su lenta erosión ha llevado a Berthe a defender que el descenso demográfico casi ininterrumpido que padece Navarra entre 1348 y 1451 sólo en parte es atribuible a las grandes crisis de mortalidad, o lo que es igual, a la mortalidad directa. Los repetidos ataques de la enfermedad y los no menos frecuentes del hambre -que habitualmente la acompañase habrían traducido según el historiador francés en un estado de degeneración interna del que el descenso de la natalidad sería el resultado más trascendente. La disminución de los nacimientos no se debería a una baja

45 AGN. Papeles sueltos, segunda serie. Legajo 9, carpeta 89. La interesada exponía a Comptos que "eilla, por quoanto es biuda de grandes tiempos aqua, mantenia su casa et su laurança con el trabaillo et esfuerç de su nieto Martin Ferrandiz, qui fue fijo de su hija que fue, el quoal dexo quoatro creaturas et una de aqueillas en la tota et las otras de menor hedat de cada siete aynos poco mas o menos, las quoales cria la dicha doyna Hurraqua. Et que maguer eilla sea bieia quesi ciega que no puede beer ni andar...". 
fecundidad, sino al envejecimiento de unas poblaciones que ven desaparecer periódicamente sus generaciones más jóvenes y la abundancia de los hogares desechos. En resumen, sería la alteración del régimen demográfico producido entre 1347 y 1368 lo que explicaría el decrecimiento continuo a partir de la primera mitad del cuatrocientos ${ }^{46}$.

Los datos por nosotros recabados vienen a confirmar el «debilitamiento demográfico» postulado por Berthe. La pirámide de población obtenida a partir de la encuesta sobre pecheros reales (1433-1437) confirma la existencia de un estrangulamiento en las generaciones adolescentes debido sin duda a los efectos de las pasadas crisis. Como veíamos en el apartado correspondiente, el número de adolescentes es, durante esos años, anormalmente bajo, lo cual no podía sino repercutir negativamente en la natalidad a corto plazo. Además, a la alta mortalidad infantil y a la recurrencia de las epidemias en los años siguientes (1441-1442 y 1451-1452) se sumaría a mitades de siglo los devastadores efectos de la guerra civil, que seguramente impidieron la recuperación e incluso hundieron los indicadores demográficos aún más.

Esta explicación de la crisis demográfica bajomedieval justifica el retardo en la recuperación de la población que padeció el reino en comparación con las regiones vecinas, pero no arroja mucha luz sobre los mecanismos que actuaron en su superación. ¿Cuándo y por qué se produjo un incremento de los nacimientos suficiente como para hacer que a finales del siglo XV el crecimiento demográfico estuviese lo suficientemente consolidado como para arrojar las cifras que hallamos en 1514 ?. Son preguntas a las que aún hay que buscar respuesta.

Lo que en todo caso parece estar fuera de toda duda es que, con el transcurrir del siglo XVI, el impacto de las pestes tanto en la mortalidad directa como en la natalidad fue reduciéndose progresivamente. Los ataques fueron menos frecuentes y más localizados a la vez que las medidas puestas en marcha para combatirlos aminoraron sus efectos. La reconstrucción de la evolución de los bautismos desde 1535 que realizamos en su día 47 muestran ese pequeño impacto sobre el número de nacimientos y cómo el progresivo incremento de la mortalidad no tuvo a la peste como su principal causa. De hecho, la llamada "Peste Atlántica" de 1599-1601 -que en Castilla puede colocarse entre las grandes pandemias europeas de los tiempos modernos- tuvo unos efectos mucho menos traumáticos sobre la población navarra. En todo caso ésta no fue sino una manifestación externa, espectacular incluso, de un proceso de signo adverso que viene gestándose desde el último cuarto de siglo.

\footnotetext{
46 BERTHE (1991): 51-58.

47 MONTEANo (1999): 66 y ss.
} 


\section{BIBLIOGRAFÍA MENCIONADA}

BERTHE, Maurice (1975): "La famine et la mort dans les campagnes du royaume de Navarre au XIve siècle", La mort au Moyen Âge, pp. 67-80 (Coloquio de la Sociedad de Historiadores Medievalistas de la Enseñanza Pública Superior), Estrasburgo, 1977.

- (1977): Les paysans du royayme de Navarre de la fin du xme siècle au milieu de xve siècle. Recherche de démographie et d'histoire sociale, Tesis doctoral presentada en Septiembre de 1979 en la Universidad de Toulouse-Le Mirail.

- (1984): Famines et épidemies dans les campagnes navarraises à la fin du Moyen Age, 2 vols., Collection "Feodalisme", Paris, SFIED, 1984.

- (1991): Fams y epidèmies al camp navarrès als segles XIV i XV, Barcelona, L'Avenç, 1991.

BIGET, J.L., y TRICARD, J. (1981); “Livres de raison et démographie familiale en Limousin au xve siecle", Annales de démographie historique, 1981, pp. 59-72.

BILBAO, Luis Maria, y FERNANDES DE PINEDO, Emiliano (1978): «En torno al problema del poblamiento y la población del País Vasco en la Edad Media», Homenaje a Julio Caro Baroja, pp. 131-160, Madrid, CIS, 1978.

Blockmans, W., y Dubois, H. (1997): "Les temps des crises (xive et xve siècles)". Histoire des populations de l'Europe. I. Des origines aux prémices de la révolution démographique, Bardet y Dupaquier (Dir.), pp. 185-217, París, Fayard, 1997.

Carrasco Perez, Juan (1973): La población de Navarra en el siglo XIV, Pamplona, EUNSA, 1973.

Floristan ImIzCOZ, Alfredo (1982): La Merindad de Estella en la Edad Moderna: los hombres y la tierra, Pamplona, Gobierno de Navarra, 1984.

Fossier, Robert (1984): Historia del campesinado en el occidente medieval (siglos Xi-XIV), Barcelona, Crítica, 1985.

—_ (1991): La sociedad medieval, Barcelona, Crítica, 1996.

Germain, R. (1995): “Le feu, un comportement social (Bourbonnais, xive- debut xvie siècle)", Population et dèmografhie au Moyen Age, pf. 27-50. París, Comité des travaux historiques et scientifiques, 1995.

HeNRY, Louis (1980): Manual de demografia histórica, Barcelona, Critica, 1983.

HERLIHY, D. (1967): Medieval and Renaissance Pistoia, 1967.

- (1973): "The population of Verona in de first century of Venetian rule", Renaisance Venice, 1973.

- y KLAPISCH-ZUBER, Ch. (1978): Les toscans et leurs familles, une étude du catasto florentin de 1427, París, 1978.

LEROY, Béatrice (1984): «Ruina y reconstrucción. Los campos y las ciudades de Navarra en la segunda mitad del siglo xIV", Hispania, núm. 157 (1984), pp. 237-261, Madrid, CSIC, 1984.

MiKElARENA PEÑA, Fernando (1990): “Transformaciones económicas y demográficas en el norte de Navarra en los siglos XVI y XVII", Segundo Congreso de la Asociación de Demografía Histórica, Alicante, Instituto de Cultura Juan Gil Albert, 1991.

Monteano Sorbet, Peio J. (1996): "Navarra de 1366 a 1428: población y poblamiento", Revista Príncipe de Viana, núm. 208 (mayo-agosto), pp. 307-343. Pamplona, Gobierno de Navarra, 1996.

- (1999): Los navarros ante el hambre, la peste, la guerra y la fiscalidad. Siglos xv y xvi, Pamplona, Universidad Pública de Navarra, 1999.

- (2000-1): "La población navarra en los siglos XIV, XV y XVI», Boletín de la Asociación de la Demografia Histórica, XVIII-I, pp. 29-70, Zaragoza, ADEH, 2000.

- (2000-2): "La población navarra a comienzos del siglo xVl: el Recuento de casas de 1514", Príncipe de Viana, núm. 220, pp. 407-431, Pamplona, Gobierno de Navarra, 2000.

- (2001): "La Peste Negra en Navarra. La catástrofe demográfica de 1347-1349", Revista Príncipe de Viana, núm. 222 (enero-abril), pp. 87-120, Pamplona, Gobierno de Navarra, 2001.

Perez Moreda, Vicente (1980): Las crisis de mortalidad en la España interior. Siglos XVI-XIX, Madrid, Siglo XXI, 1980. 